\title{
Docentenprofessionalisering door integratie van theoretisch leren, ervaringsleren, intervisie en reflectie
}

\author{
M.J.B. Govaerts, T.J.H.I. Bisscheroux, A.C.M. Merkx
}

\section{Samenvatting}

Inleiding: Docentprofessionaliseringstrajecten zijn belangrijke instrumenten bij de kwaliteitsborging van opleidingen. Traditionele scholingsprogramma's zijn veelal vormgegeven vanuit een opvatting dat leren vooral plaatsvindt in een educatieve context (off-the-job, onder (bege)leiding van een expert). Er zijn argumenten voor andere benaderingen. In dit artikel wordt een docentprofessionaliseringsprogramma beschreven dat tegemoet komt aan de kritiek op traditionele benaderingen door een integrale, longitudinale benadering met een sterke nadruk op werkplekleren.

Opzet: Beschreven wordt een driejarig intern scholingstraject voor een grote groep docenten, waarin diverse vormen van leren worden gecombineerd: ervaringsleren, interactie met collega's, kritische reflectie op het eigen handelen en theoretisch leren. Centraal in het traject staat de ondersteuning van docenten bij het structureren van de leerervaringen die zij opdoen tijdens het werk.

Resultaten: Bij de evaluatie na afloop van het eerste jaar geven deelnemers aan het traject zeer leerzaam te vinden. Docenten voelen zich beter toegerust voor hun taken en zijn zich meer bewust van hun rol als docent in de opleidingsorganisatie. Vooral de relevantie van de inhoud voor de dagelijkse praktijk, de directe toepasbaarheid van de scholing en de interactie in intercollegiale coachingsgroepen worden als zeer waardevol ervaren.

Conclusie: Het geschetste model lijkt een veelbelovende vorm van docentprofessionalisering, waarbij meer doelstellingen tegelijkertijd gerealiseerd kunnen worden. Deze aanpak kan een belangrijke bijdrage leveren aan het ontwikkelen van de onderwijskundige expertise van docenten en de basis vormen voor een organisatieklimaat waarin professioneel leren vanzelfsprekend is. (Govaerts MJB, Bisscheroux TJHI, Merkx ACM. Docentenprofessionalisering door integratie van theoretisch leren, ervaringsleren, intervisie en reflectie. Tijdschrift voor Medisch Onderwijs 2004;23(2):91-99.)

\section{Inleiding}

"In all phases of education, student achievement correlates with the quality of the teacher. If we don't focus on the quality of teaching, other reform efforts will not bring what we were hoping for." 1

Kwaliteit van onderwijs staat of valt met de kwaliteit van docenten. Docentprofessionaliseringstrajecten zijn dan ook belangrijke instrumenten bij de kwaliteitsborging van opleidingen. ${ }^{2}$ Gangbare docentprofessionaliseringsprogramma's in het medisch onderwijs bestaan uit een (beperkt) aantal trainingen en/of workshops, waarbij in korte tijd en vaak zonder follow-up, een aantal onderwijskundige principes, docentvaardigheden of specifieke onderwerpen met betrekking tot curriculumontwikkeling aan bod komen. Deze trajecten zijn vooral gericht op 'offthe-job-leren' onder leiding van een expert. De resultaten van deze vorm van docentenprofessionalisering zijn vaak teleur- 
stellend. ${ }^{3}$ Een combinatie van factoren ligt hieraan ten grondslag.

Medische opleidingen worden gekenmerkt door een docentencorps dat niet of slechts beperkt onderwijskundig-didactisch geschoold is. Docenten worden veelal aangenomen op basis van hun kwaliteiten op het gebied van patiëntenzorg en/of onderzoek. In de scholing voor deze 'startende' docenten wordt in de regel weinig aandacht besteed aan de specifieke positie van de docent in de organisatie en de kwalificatie-eisen die aan docenten worden gesteld. Dit heeft consequenties voor de mate waarin docenten de scholingsactiviteiten als relevant en motiverend ervaren, en de opgedane kennis daadwerkelijk zullen toepassen in de praktijk. ${ }^{3}$

Teleurstellende scholingsresultaten zijn daarnaast voor een belangrijk deel te wijten aan transferproblemen. Docenten blijken niet vaak in staat om de in de trainingscontext opgedane kennis en ervaring toe te passen in de eigen onderwijssituatie. Voor veel docenten komt bovendien de inhoud van de trainingen niet overeen met eigen opvattingen over leren en docentrollen. Deze zijn vaak gebaseerd op wat zij zelf als student hebben ervaren. ${ }^{4}$ Nieuwe ontwikkelingen in het medisch onderwijs, zoals de invoering van studentgecentreerd onderwijs, vragen echter om nieuwe docentrollen en andere visies op leren en onderwijs. Korte cursussen bieden doorgaans weinig gelegenheid stil te staan bij de onderliggende principes van onderwijsvernieuwingen en opvattingen die ten grondslag liggen aan docentgedrag. Daarom worden onderwijsvernieuwingen vaak oppervlakkig doorgevoerd. ${ }^{5}$ Aanvullende activiteiten na afloop van de cursus, bijvoorbeeld in de vorm van oefening, steun en feedback op de werkplek, zijn noodzakelijk om gedragsverandering gedurende langere tijd te handhaven. 36 Uit onderzoek blijkt dat leren op de werk- plek vooral plaatsvindt naar aanleiding van activiteiten die uitdagen tot kritische reflectie en interactie met anderen. ${ }^{7-8}$

Veel voorkomende problemen bij de implementatie van scholingsprogramma's, ten slotte, hebben te maken met gebrekkige randvoorwaarden. Vaak ontbreekt adequate ondersteuning door het management, met als gevolg dat er onvoldoende tijd en middelen ter beschikking staan voor docentscholing en/of docenten onvoldoende in de gelegenheid gesteld worden te participeren in relevante scholingsbijeenkomsten. Uit onderzoek blijkt echter dat leren vooral succesvol is als het leren verbonden wordt aan organisatieprioriteiten en indien de organisatie een langdurige en continue betrokkenheid toont. ${ }^{3} 7$ Het betrekken van management en direct leidinggevenden bij de ontwikkeling van scholingsprogramma's is een essentiële voorwaarde voor de effectiviteit.

Aan de Vroedvrouwenschool te Kerkrade werd, in samenwerking met de Universiteit Maastricht, een innovatief scholingstraject ontwikkeld op basis van recente inzichten in het vormgeven van scholingsprogramma's in organisaties. In dit artikel wordt een docentprofessionaliseringsprogramma beschreven dat gekenmerkt wordt door een integraal, longitudinaal karakter met een sterke nadruk op ervaringsleren, kritische reflectie en coaching in het werk.

\section{Docentprofessionalisering aan de Vroedvrouwenschool}

\section{Situatieschets}

De Vroedvrouwenschool Kerkrade (VVS), opleiding tot verloskundige, is een kleine, zelfstandige onderwijsorganisatie met een medische opleiding op HBO-niveau. Het onderwijs aan de VVS is vormgegeven volgens de principes van probleemgestuurd onderwijs (PGO). Op basis van hun takenpakket maken docenten deel uit van één 
van de teams die verantwoordelijk zijn voor respectievelijk theoretisch onderwijs, vaardigheidsonderwijs en stagegewijs praktijkonderwijs. De docentenstaf bestaat merendeels uit verloskundigen die noch op basis van initiële opleiding noch op grond van werkervaring beschikken over vereiste docentcompetenties. Vóór de start van het nieuwe professionaliseringstraject was docentscholing vooral gericht op het verwerven van specifieke vaardigheden via korte tutortrainingen en trainingen in blok- en taakconstructie. In 2001 werd echter zowel door docenten als door het opleidingsmanagement een behoefte aan extra scholing geconstateerd, hetgeen leidde tot een heroriëntatie op het professionaliseringsbeleid van de opleiding. Binnen drie jaar was het aantal docenten met ca. $45 \%$ gegroeid, terwijl bovendien het curriculum ingrijpend was veranderd. De herinrichting van het $\mathrm{H}$-vormig opleidingscurriculum naar een Z-vormig model stelde hoge en vaak nieuwe eisen aan docenten wat betreft onderwijsontwikkeling en onderwijsuitvoering. Theoretisch en praktisch onderwijs moesten opnieuw worden vormgegeven en beter op elkaar afgestemd en nieuwe werkvormen en toetsvormen moesten worden ontwikkeld. Daarom werd besloten tot de ontwikkeling van een intern, grootschalig traject in samenwerking met de eerstegraads lerarenopleiding van de Universiteit Maastricht. De belangrijkste uitgangspunten en hun uitwerking in dit driejarige scholingstraject zijn samengevat in tabel 1. Enkele aspecten worden hieronder toegelicht.

\section{Het voortraject: draagvlak en rand- voorwaarden}

De ontwikkeling en de implementatie van het traject vond plaats onder verantwoordelijkheid van een projectgroep. In de eerste fase stond het creëren van draagvlak voor het scholingstraject centraal. Frequent overleg met het opleidingsmanagement was gericht op het expliciteren van de verwachtingen bij het management ten aanzien van de scholing en op de randvoorwaarden van tijd en geld voor het traject. Het zichtbaar maken van de extra scholingsactiviteiten in het takenpakket en de roosterplanning van de deelnemers werd gezien als essentieel. Ook werden de deelnemers vroeg bij de ontwikkeling van het traject betrokken. Eerst werd de deelnemers schriftelijk en mondeling informatie verstrekt over de eisen van het opleidingsmanagement aan docentkwalificaties en de te vervullen docentrollen. De bespreking hiervan resulteerde in een gezamenlijk gedragen visie op docentrollen en -taken in de organisatie. Op basis hiervan werden specifieke scholingswensen bij de deelnemers met interviews geïnventariseerd. Hieruit bleek een grote behoefte aan vaardigheden voor de onderwijsuitvoering en begeleiding van individuele studenten. Door alle deelnemers werd benadrukt dat het scholingsaanbod vooral toepassingsgericht moet zijn, aansluitend bij de dagelijkse praktijk, met secundair aandacht voor theoretisch leren. Ook bleek er grote behoefte aan feedback op het handelen als docent en ruimte voor uitwisseling van ervaringen met collega's. Op basis van dit vooroverleg heeft de projectgroep een voorstel geformuleerd voor de inhoud en opzet van het traject, dat weer met alle betrokkenen is besproken.

\section{Inhoud en opzet van het scholings- programma}

Het programma voor het eerste jaar werd door de projectgroep gedetailleerd uitgewerkt; het vervolg slechts in grote lijnen. Hierdoor behouden de deelnemers de mogelijkheid om op grond van ervaringen en actuele scholingsbehoefte, het programma samen met de projectgroep vorm te geven. 
Tabel 1. Schematische weergave van de belangrijkste uitgangspunten bij het docentprofessionaliseringstraject VVS en hun uitwerking in het traject.

\begin{tabular}{|c|c|}
\hline Uitgangspunt & Realisatie door ... \\
\hline $\begin{array}{l}\text { Actieve deelname door alle } \\
\text { (staf)docenten }\end{array}$ & $\begin{array}{l}\text { Creëren breed draagvlak; intensieve communicatie in ontwikkelfase. } \\
\text { Gemeenschappelijke visie op docentrollen in de organisatie. } \\
\text { Continue ondersteuning van opleidingsmanagement in de vorm van: } \\
\text { - beschikbaar budget; } \\
\text { - opname van scholing in taakinzet en jaarrooster ( } 80 \text { klokuren per jaar). }\end{array}$ \\
\hline $\begin{array}{l}\text { Scholing ten behoeve van } \\
\text { ontwikkeling docentcom- } \\
\text { petenties op niveau } \\
\text { HBO-docent }\end{array}$ & $\begin{array}{l}\text { Samenwerking eerstegraads lerarenopleiding Universiteit Maastricht. } \\
\text { Expertfunctie m.b.t. bewaking niveau in de vorm van: } \\
\text { - docentkwalificaties; } \\
\text { - opdrachten, literatuur onderwijskunde/didactiek; } \\
\text { - scholing coaches. }\end{array}$ \\
\hline $\begin{array}{l}\text { Scholing op maat: } \\
\text { - voor de individuele deel- } \\
\text { nemer }\end{array}$ & $\begin{array}{l}\text { Differentiatie in scholingsaanbod op basis van twee doelgroepen: } \\
\text { - traject beginnend docent: startkwalificaties HBO-docent; } \\
\text { - traject gevorderd docent: coachingsvaardigheden. }\end{array}$ \\
\hline $\begin{array}{l}\text { voor de opleidingsorga- } \\
\text { nisatie }\end{array}$ & $\begin{array}{l}\text { Inhoud van traject in samenspraak met alle betrokkenen: docenten, direct } \\
\text { leidinggevenden/management: } \\
\text { - 3-jarig traject met jaarthema's op micro-, meso-, resp. macroniveau: } \\
\text { docent, onderwijsuitvoering en leerproces van de student. } \\
\text { docent, onderwijsontwikkeling en opleidingsorganisatie. } \\
\text { docent, externe ontwikkelingen en opleidingscurriculum. }\end{array}$ \\
\hline & $\begin{array}{l}\text { Flexibiliteit in leerproces door: } \\
\text { - uitwerking opdrachten afhankelijk van taken binnen de opleiding; } \\
\text { - persoonlijke leerdoelen op basis van eigen ervaringen en doelstellingen } \\
\text { traject. }\end{array}$ \\
\hline & $\begin{array}{l}\text { Integratie in het primaire proces door: } \\
\text { - leren gebaseerd op ervaringen/casuïstiek uit eigen werkomgeving; } \\
\text { - producten direct toepasbaar in opleiding. }\end{array}$ \\
\hline Leren in de organisatie & $\begin{array}{l}\text { Coaching van beginnend docenten door seniordocenten ('mentorsys- } \\
\text { teem'). } \\
\text { Intercollegiale coaching ('peer coaching'/ intervisie). } \\
\text { Organiseren van momenten voor interactie en reflectie in de vorm van: } \\
\text { - uitwisseling ervaringen, opvattingen; } \\
\text { - directe observatie en feedback op uitvoering docenttaken; } \\
\text { - bespreking ervaringen op basis van reflectiemodel Korthagen. } \\
\text { Indien relevant: theoretische onderbouwing en skillstraining. }\end{array}$ \\
\hline
\end{tabular}

In het traject zijn twee doelgroepen onderscheiden op grond van verschillen in reeds verworven docentkwalificaties. Docenten die al beschikken over relevante kwalificaties zijn ingezet als coaches van beginnende docenten. De scholing voor deze coaches is gericht op het verwerven van kennis en vaardigheden die noodzakelijk zijn bij het coachen van collegadocenten op de werkplek in een train-de- 
trainers traject, naast verdieping en verbreding van onderwijskundig-didactische kennis. Deze scholing sluit daarmee aan op het persoonlijke ontwikkelingsniveau van en de behoefte aan verdere ontwikkeling bij deze docenten.

Voor de groep 'beginnende' docenten is het traject gericht op het verwerven van kwalificaties op het niveau van een startende HBO-docent. In het eerste jaar van het traject ligt de nadruk op onderwijsuitvoering en de rol van de docent als begeleider van het leerproces van de student. Belangrijke thema's in het eerste jaar zijn:

- Het begeleiden van het leerproces (tutorschap, het voeren van reflectiegesprekken, leergesprekken).

- Het creëren van een leeromgeving (het schrijven van PGO-taken, het ontwerpen van een vaardigheidstraining, het geven van presentaties/colleges).

- Toetsen en evalueren (de constructie van toetsvragen, het voeren van stagebeoordelingsgesprekken).

In het tweede jaar ligt de nadruk op complexere onderwijsontwikkelingstaken en de rol van de docent in de organisatie (het ontwerpen van vaardigheidslijnen, blokconstructie, projectmatig werken); in het derde jaar op externe ontwikkelingen en de consequenties daarvan voor het opleidingscurriculum.

In het traject worden verschillende werkvormen gehanteerd. Zo is een aantal bijeenkomsten met externe experts ingepland, in de vorm van specifieke korte trainingen of workshops rond een bepaald thema (het construeren toetsvragen, reflecteren). Daarnaast werken docenten aan opdrachten, ontleend aan de dagelijkse onderwijspraktijk binnen de VVS. Elke opdracht is gerelateerd aan één van de gekozen jaarthema's. Terugkerende doelstellingen bij alle opdrachten zijn:
- Het bespreken van eigen ervaringen en het formuleren van persoonlijke leerdoelen op basis van aan de eigen werksituatie ontleende casuïstiek. Het vertalen van de breed geformuleerde opdracht naar opdrachten voor de eigen werksituatie.

- Zelfstudie. Opdrachten gaan vergezeld van relevante overzichts- en onderzoeksliteratuur.

- Het vervaardigen van producten die direct toepasbaar zijn in de opleiding: PGO-taken, protocollen ten behoeve van het vaardigheidsonderwijs, toetsvragen ten behoeve van blok- en voortgangstoetsen, et cetera. Docenten gebruiken het eigen takenpakket en werksituatie als basis voor de uitwerking van de opdracht.

- Het vragen van feedback aan studenten of collega's op het handelen als docent c.q. het product van de opdracht. Deelnemers in het traject observeren elkaar, bijvoorbeeld bij het vervullen van tutorschappen of bij het geven van colleges, en leggen toetsvragen en andere onderwijsproducten ter beoordeling voor aan elkaar en aan studenten. De feedback wordt besproken met collega-docenten en vormt een belangrijke basis voor het leren, individueel en in de intercollegiale coachingsgroep.

De belangrijkste werkvorm wordt gevormd door intercollegiale coachingsgroepen. Deze coachingsgroepen bestaan uit vier à vijf docenten in vaste samenstelling, afkomstig uit verschillende teams. Zij komen regelmatig bijeen en bespreken onder begeleiding van de coach de opdrachten en leerervaringen. Elke opdracht komt gespreid over twee bijeenkomsten aan bod. In de eerste bijeenkomst staat het uitwisselen van ervaringen naar aanleiding van de gepresenteerde casuïstiek centraal en worden persoonlijke leerdoe- 
len geformuleerd. In een volgende bijeenkomst bespreken docenten de gemaakte opdrachten en de feedback, en reflecteren zij op hun eigen en andermans handelen als docent. Opvattingen over leren en de consequenties daarvan voor de wijze waarop docenttaken worden vervuld, krijgen veel aandacht. Het bespreken van de leer-ervaringen van de deelnemers wordt gestructureerd door het 'Reflectiemodel van Korthagen' als schema te gebruiken bij de bespreking. ${ }^{9}$ Binnen dit spiraalmodel wordt het leren van ervaringen aan de hand van reflectievragen gefaseerd doorlopen. In het model staan centraal het terugblikken op een ervaren situatie, het formuleren en analyseren van essentiële aspecten in deze situatie, en het ontwikkelen van handelingsalternatieven, voornemens en leerwensen. Ten slotte worden docenten door voorgestructureerde werkbladen ondersteund bij het zichtbaar maken van hun leerproces. De werkbladen stimuleren de docenten tot het schriftelijk formuleren van persoonlijke leerdoelen, leerervaringen en eventuele aandachtspunten voor de toekomst. Deze werkbladen vormen, samen met de uitwerking van de opdrachten, de basis voor een persoonlijk portfolio. Het bevorderen van de veiligheid in de groep, het structureren van het reflectieproces en het stimuleren van zelfsturend leren behoren tot de taken van de coach.

\section{Evaluatie}

Het eerste jaar van het scholingstraject is geïmplementeerd in academiejaar 20012002. Na afloop van het eerste jaar is het traject mondeling en schriftelijk geëvalueerd. De schriftelijke evaluatie onder de deelnemers leverde een positief beeld op (tabel 2). Docenten zijn tevreden over de gekozen opzet en beschouwen het leerklimaat in de intercollegiale coachingsgroepen als veilig en productief. De relevantie van de inhoud en de directe toepasbaarheid van de resultaten in het onderwijs worden zeer gewaardeerd. Docenten geven vrijwel zonder uitzondering aan meer inzicht te hebben in leerprocessen en nieuwe inzichten toe te passen bij de uitvoering van hun taken. Het zelfvertrouwen is toegenomen. Tegelijkertijd realiseren docenten zich het belang van een goede oriëntatie op hun taken, waarbij het beargumenteren en onderbouwen van gemaakte keuzes steeds meer nadruk krijgt. Daarnaast zijn veel docenten zich meer bewust van het belang van samenwerking, niet alleen ten behoeve van de ontwikkeling en uitvoering van onderwijs, maar vooral ook als bron van leren en het zichtbaar maken van kennis in de organisatie. Door te werken aan een diversiteit aan opdrachten, afkomstig uit de aandachtsgebieden van de verschillende docententeams, maar ook door de uitwisseling van ervaringen in de heterogeen samengestelde coachingsgroepen, krijgen docenten meer inzicht in de structuur van de opleiding als geheel. Het resultaat is een kritischer kijk op de wijze waarop onderwijsontwikkeling en -uitvoering worden gerealiseerd en de uitgangspunten die daaraan ten grondslag liggen.

Het minst positief zijn docenten over de wijze waarop het leren is voorgestructureerd in de aangereikte werkbladen. Het gebruik van de werkbladen wordt als tijdrovend, niet altijd zinvol en enigszins schools ervaren.

Evaluatie door de coaches levert vergelijkbare bevindingen op. Zij geven aan een beter beeld te hebben van problemen en dilemma's bij beginnend docenten en de specifieke organisatiekenmerken die daarop van invloed zijn. Dit leidt ertoe dat de coaches in toenemende mate in staat zijn om een actieve bijdrage te leveren aan de ontwikkeling van het scholingsprogramma. 
Tabel 2. Gemiddelde score (met standaarddeviatie) op vragen bij de evaluatie van het docentenprofessionaliseringstraject 2001-2002.

\begin{tabular}{lcc}
\hline & $\begin{array}{c}\text { Gemiddelde } \\
\text { score }\end{array}$ & $\begin{array}{c}\text { Standaard- } \\
\text { deviatie }\end{array}$ \\
\hline 1. Deelname aan het traject heeft mijn ontwikkeling als docent gestimuleerd & 4,6 & 0,5 \\
2. De interviews en verstrekte informatie vormden een goede voorbereiding & 4,0 & 0,8 \\
op het traject & 3,8 & 1,1 \\
3. Deelname aan het traject interfereerde niet met mijn andere taken & 4,9 & 0,4 \\
4. De gekozen onderwerpen waren relevant voor mijn werkzaamheden als & 4,5 & 0,7 \\
docent & 4,0 & 0,7 \\
5. De resultaten van het traject waren direct toepasbaar in de praktijk & 4,8 & 0,4 \\
6. Deelname aan het traject heeft mijn werkwijze als docent veranderd. & 4,6 & 0,6 \\
7. Het leren in de intercollegiale coachingsgroep verliep prettig & 4,4 & 0,5 \\
8. De bijeenkomsten in de coachingsgroep waren productief & 4,5 & 0,5 \\
9. De bijeenkomsten in de coachingsgroep waren motiverend & 4,6 & 0,5 \\
10. In de coachingsgroep ontving ik voldoende feedback op mijn functioneren & \\
als docent & 4,2 & 0,6 \\
11. De feedback op mijn functioneren als docent vond ik leerzaam & 4,7 & 0,7 \\
12. Er was voldoende aandacht voor reflectie op mijn werkwijze als docent & & 0,8 \\
13. De aangereikte literatuur in het traject was bruikbaar & & \\
14. De voorgestructureerde werkbladen vormden een zinvol hulpmiddel bij het & 3,8 & \\
$\quad$ leren in dit traject & &
\end{tabular}

Respons: $80 \%$ (totaal aantal deelnemers 18 ).

\section{Conclusie}

In bovenstaande is een schets gegeven van een longitudinaal, geïntegreerd scholingstraject met een sterke nadruk op het structureren van leerervaringen van docenten tijdens het werk. De resultaatgerichte opdrachten, resulterend in feedback, en de uitwisseling van ervaringen in de intercollegiale coachingsbijeenkomsten stimuleren docenten tot kritische reflectie op hun handelen. Docenten ervaren de combinatie van theoretisch leren, ervaringsleren en reflectie als zeer waardevol voor hun professionele ontwikkeling. Hierbij moet echter de kanttekening gemaakt worden dat de evaluatieresultaten uitsluitend gebaseerd zijn op satisfactie van de deelnemers. In hoeverre het traject daadwerkelijk leidt tot verbetering van de onderwijskwaliteit dient nader onderzocht te worden.
Schaalwaarde: $1=$ volledig oneens; $5=$ volledig eens.

Bij de implementatie van het traject zijn als succesfactoren van essentieel belang gebleken:

- Het creëren van draagvlak tijdens de ontwikkelfase van het traject door intensieve communicatie met alle betrokkenen. Actieve en blijvende betrokkenheid van het opleidingsmanagement, resulterend in het beschikbaar stellen van tijd, geld en ruimte voor scholing in het takenpakket van deelnemers, blijkt een essentiële voorwaarde voor de effectiviteit van scholingsprogramma's. Vooroverleg met deelnemers biedt gelegenheid om eventuele weerstanden tegen scholing weg te nemen en te komen tot een gemeenschappelijke visie op docentrollen en bijbehorende kwalificatie-eisen.

- Een toepassingsgericht karakter van de scholing, waarbij werkervaring en actuele 
vragen uitgangspunt vormen voor het leren. Opdrachten zijn gebaseerd op de dagelijkse onderwijspraktijk en resulteren in direct toepasbare kennis en onderwijsproducten.

- Het organiseren van leermomenten, waarin de uitwisseling van ervaringen, feedback en kritische reflectie centraal staan.

- Intercollegiale coaching, waarbij beginnende docenten in hun leerproces begeleid worden door senior-docenten en tevens in staat worden gesteld van elkaar te leren.

Deze succesfactoren liggen ten grondslag aan de veiligheid van het leerklimaat, de hoge motivatie van de deelnemers en de waardering voor het scholingstraject.

Het geschetste model lijkt een veelbelovende vorm van docentprofessionalisering, waarbij meer doelstellingen tegelijkertijd gerealiseerd kunnen worden wat betreft de ontwikkeling van zowel individuele deelnemers als de organisatie. Dergelijke langdurige en grootschalige professionaliseringstrajecten, met aandacht voor vaardigheden die noodzakelijk zijn voor leren tijdens het werk, kunnen tevens de basis vormen voor een organisatieklimaat waarin professioneel leren vanzelfsprekend is. ${ }^{10}$

\section{Literatuur}

1. Harden RM, Crosby J. The good teacher is more than a lecturer - the twelve roles of the teacher. AMEE guide no 20. Med Teach 2000;22:334-47.
2. Stuyt P. Medische docenten: tijd voor kwaliteit. Tijdschrift voor Medisch Onderwijs 2002;21:183-7.

3. Witziers B. Het effectiviteitsvraagstuk rond bedrijfsopleidingen. In: Poell R, Kessels J, editors. Human resource development. Organiseren van het leren. Groningen: Samsom; 2001. p. 385-98.

4. Irby DM. Models of faculty development for problem-based learning. Advances in Health Sciences Education 1996;1:69-81.

5. Bland C. Curricular change in medical schools: how to succeed. Acad Med 2000;75:575-94.

6. Wilkerson L, Irby DM. Strategies for improving teaching practices: a comprehensive approach tot faculty development. Acad Med 1998;73:387-96.

7. Kwakman CHE. Leren van docenten tijdens de beroepsloopbaan. Studies naar professionaliteit op de werkplek in het voortgezet onderwijs [dissertatie]. Nijmegen: Katholieke Universiteit Nijmegen; 1999.

8. Kwakman K. Leren van professionals tijdens de beroepsuitoefening. In: Poell R, Kessels J, editors. Human resource development. Organiseren van het leren. Groningen: Samsom; 2001. p. 229-42.

9. Korthagen FAJ. Leren reflecteren, naar systematiek in het leren van je werk als docent. In: Fonderie I, Hendriksen J, editors. Begeleiden van docenten. Baarn: Nelissen; 1998.

10. Bolhuis S. Professioneel leren: wat is het en hoe bevorderen we het? Tijdschrift voor Medisch Onderwijs 2002;21:173-82.

\section{De auteurs:}

Mw. M.J.B. Govaerts is beleidsmedewerker onderwijs aan de opleiding tot verloskundige, Vroedvrouwenschool Kerkrade.

Dhr. T.J.H.I. Bisscheroux is opleidingskundige aan de Hogeschool Zuyd en destijds coördinator eerstegraads lerarenopleiding, Universiteit Maastricht.

Mw. A.C.M. Merkx is docent aan de opleiding tot verloskundige, Vroedvrouwenschool Kerkrade.

\section{Correspondentieadres:}

Mw. M.J.B. Govaerts, Vroedvrouwenschool Kerkrade, Wijngracht 47, 6461 AL Kerkrade, tel: 045-5450616, fax: 045-5451155,m.govaerts@vroedvrouwenschool.nl.

\section{Summary}

Introduction: Faculty development programmes are essential to ensure continuous quality improvement in medical education. The prototypical faculty development programme is a series of workshops or seminars in a formal educational setting, requiring time away from ongoing responsibilities. They are often limited by their brevity, lack of follow up, and the inability to sustain change over time. In an attempt to overcome such drawbacks, Kerkrade Midwifery School has developed a longitudinal, integrated programme based on principles of experiential and professional learning.

Method: The authors describe a three-year faculty development programme that integrates the principles of experiential learning, collaborative and interactive learning, reflective practice and educational theory. The main purpose of the programme is to create work-based learning opportunities and to support teachers in the structuring of their learning experiences. 
Results: Evaluation results after the first year show that the participants are very enthusiastic about the programme. The participants indicate that their professional expertise has grown and that their self-efficacy as well as their awareness of their role as a teacher in the organization has increased. The relevance and the practical applicability of the programme as well as the learning and the interaction in the peer group are seen as decisive in the programme's successful implementation.

Conclusion: The programme seems to be a promising format for faculty development, linking individual and organizational needs. Not only does it seem to enhance the professional skills of the teachers, it also promotes initiatives in organizational development towards a learning community. (Govaerts MJB, Bisscheroux TJHI, Merkx ACM. An integrated faculty development model: experiential and professional learning. Dutch Journal of Medical Education 2004;23(2):91-99.) 